\title{
Dysregulated Metabolites Serve as Novel Biomarkers for Metabolic Diseases Caused by E-Cigarette Vaping and Cigarette Smoking
}

\author{
Qixin Wang ${ }^{1}{ }^{\mathbb{D}}$, Xiangming Ji ${ }^{2}$ and Irfan Rahman ${ }^{1, *(\mathbb{D}}$ \\ 1 Department of Environmental Medicine, School of Medicine and Dentistry, University of Rochester Medical \\ Center, Rochester, NY 14642, USA; Qixin_Wang@URMC.Rochester.edu \\ 2 Department of Nutrition, Byrdine F. Lewis School of Nursing and Health Professions, Georgia State \\ University, Atlanta, GA 30302, USA; xji4@gsu.edu \\ * Correspondence: Irfan_Rahman@URMC.Rochester.edu
}

Citation: Wang, Q.; Ji, X.; Rahman, I. Dysregulated Metabolites Serve as Novel Biomarkers for Metabolic Diseases Caused by E-Cigarette Vaping and Cigarette Smoking. Metabolites 2021, 11, 345. https:// doi.org/10.3390/metabo11060345

Academic Editor: Timothy E. O’Toole

Received: 7 April 2021

Accepted: 24 May 2021

Published: 29 May 2021

Publisher's Note: MDPI stays neutral with regard to jurisdictional claims in published maps and institutional affiliations.

Copyright: ( $\odot 2021$ by the authors Licensee MDPI, Basel, Switzerland. This article is an open access article distributed under the terms and conditions of the Creative Commons Attribution (CC BY) license (https:// creativecommons.org/licenses/by/ $4.0 /)$.

\begin{abstract}
Metabolites are essential intermediate products in metabolism, and metabolism dysregulation indicates different types of diseases. Previous studies have shown that cigarette smoke dysregulated metabolites; however, limited information is available with electronic cigarette (e-cig) vaping. We hypothesized that e-cig vaping and cigarette smoking alters systemic metabolites, and we propose to understand the specific metabolic signature between e-cig users and cigarette smokers. Plasma from non-smoker controls, cigarette smokers, and e-cig users was collected, and metabolites were identified by UPLC-MS (ultra-performance liquid chromatography mass spectrometer). Nicotine degradation was activated by e-cig vaping and cigarette smoking with increased concentrations of cotinine, cotinine N-oxide, (S)-nicotine, and (R)-6-hydroxynicotine. Additionally, we found significantly decreased concentrations in metabolites associated with tricarboxylic acid (TCA) cycle pathways in e-cig users versus cigarette smokers, such as D-glucose, (2R,3S)-2,3-dimethylmalate, (R)-2-hydroxyglutarate, O-phosphoethanolamine, malathion, D-threo-isocitrate, malic acid, and 4acetamidobutanoic acid. Cigarette smoking significant upregulated sphingolipid metabolites, such as D-sphingosine, ceramide, $N$-(octadecanoyl)-sphing-4-enine, $N$-(9Z-octadecenoyl)-sphing-4-enine, and $N$-[(13Z)-docosenoyl]-sphingosine, versus e-cig vaping. Overall, e-cig vaping dysregulated TCA cycle-related metabolites while cigarette smoking altered sphingolipid metabolites. Both e-cig and cigarette smoke increased nicotinic metabolites. Therefore, specific metabolic signatures altered by ecig vaping and cigarette smoking could serve as potential systemic biomarkers for early pathogenesis of cardiopulmonary diseases.
\end{abstract}

Keywords: metabolome; TCA; lipids; e-cigarette; cigarette; biomarkers

\section{Introduction}

E-cigarette (e-cig) vaping has been increasing rapidly in the United States during recent decades since e-cig is considered a relatively safer alternative to help quit smoking [1]. The e-cig devices deliver aerosolized e-liquid with different concentrations of nicotine. The constituents from e-cig liquid are usually propylene glycol (PG) and vegetable glycerin (VG), which are generally recognized as safe (GRAS). Although PG and VG are GRAS, the aerosolized constituents have proven to be toxicants [2]. It has been known that e-cig delivers more nicotine than cigarette smoke [3,4]. Furthermore, we have shown that e-cig vapor contained various chemical constituents that can affect the downstream metabolism [5]. Cigarette smoke is known to contain thousands of toxic chemicals [6]. The chemicals generated from e-cig or cigarette smoking as xenobiotic chemicals in human organisms could dysregulate metabolomics profiles [7-10] and increase the risk of lung diseases, even lung cancers [11]. Commonly, cotinine is one of the significant metabolites during nicotine degradation, which has been used to identify the smoker or e-cig user [12]. 
We have shown circulating biomarkers are increased from e-cig users or cigarette smokers, predicting the risk of lung and heart diseases [13,14]. Our results found e-cig vaping is more associated with bioenergy synthesis (TCA cycle) than cigarette smoking, while cigarette smoking leads to upregulated sphingolipid pathways.

Bioenergy synthesis, including gluconeogenesis, glycolysis, and the TCA cycle, is one of the major metabolic reactions in mitochondrion for generating energy among all the organs/tissues. Previous studies reported that e-cig vaping and cigarette smoking inhibited bioenergy synthesis and induced mitochondrial dysfunction $[15,16]$. Mitochondrial metabolism alternation in lungs was followed by cigarette smoke exposure $[15,16]$; e-cig exposure induced mitochondrial oxidative stress and DNA damage $[17,18]$. Interestingly, a previous study explained that circulated PG would be metabolized into lactic acid in the liver and go through the TCA cycle [19]. However, no study is available to show the bioenergy synthesis-related circulating metabolites in e-cig users and cigarette smokers compared to healthy controls.

Sphingolipids are lipids that contain sphingoid structures and major constituents of the plasma membrane $[20,21]$. Recent studies have shown that sphingolipid metabolites regulate pulmonary inflammatory responses, and they are essential mediators in lung cancer [20,22]. Cigarette smoke-induced accumulation of sphingolipid metabolites in the lungs is mediated with mitophagy, necroptosis, autophagy, and oxidative stress [22-25]. Interestingly, previous reports have described dysregulated plasma sphingolipids associated with lung cancer and chronic obstructive pulmonary disease (COPD) phenotypes [26,27]. In this study, we determined the dysregulation of sphingolipid metabolites in plasma from cigarette smokers or e-cig users.

We collected plasma from healthy controls/non-smokers/non-users, e-cig users, and cigarette smokers for metabolite analysis. Our results showed that metabolites related to nicotine degradation are dysregulated in the plasma from both e-cig users and cigarette smokers. TCA cycle-related metabolites showed alternation only in the plasma of e-cig users, while sphingolipid metabolites presented dysregulation only in cigarette smokers' plasma.

\section{Results}

2.1. Global Metabolic Profiling of Plasma from Healthy Controls, E-Cig Users, and Cigarette Smokers Analyzed by UPLC-MS

We performed global metabolites profiling based on negative and positive ion modes to identify dysregulated metabolites in plasma from cigarette smokers and e-cig users through UPLC-MS (Figure 1A,B). We found a total of 1018 and 7244 metabolites that were detected in negative and positive ion modes, respectively. We further applied a multivariate analysis via the PCA model to determine the significance of metabolomics profiling in our cohorts (Figure 1C,D). In the negative ion mode UPLC-MS measurement, the absolute value of metabolites between the control and cigarette smoking groups are overlapped, while metabolites in the e-cig group show significantly different metabolites distribution (Figure 1C). Interestingly, we found overlapped metabolite distribution in the control and e-cig users' plasma in positive ion mode, and cigarette smokers showed a significant difference in dysregulated metabolites (Figure 1D).

We also screened and identified the dysregulated metabolic pathways in cigarette smoke and e-cig groups (Figure 2 and Table 1). Metabolic pathways, including nicotine degradation III, serotonin degradation, and gluconeogenesis, were altered in cigarette smoke and e-cig groups. Interestingly, the TCA cycle, D-galactose degradation, and UDP$\mathrm{N}$-acetyl-D-galactosamine biosynthesis II were found to be dysregulated in the e-cig group, while nicotine degradation IV was altered in the cigarette smoke group. Further, we identified specific dysregulated metabolites related to nicotine degradation, TCA cycle, and sphingolipid metabolism based on the normalized spectrum area (Figure 2). 
A

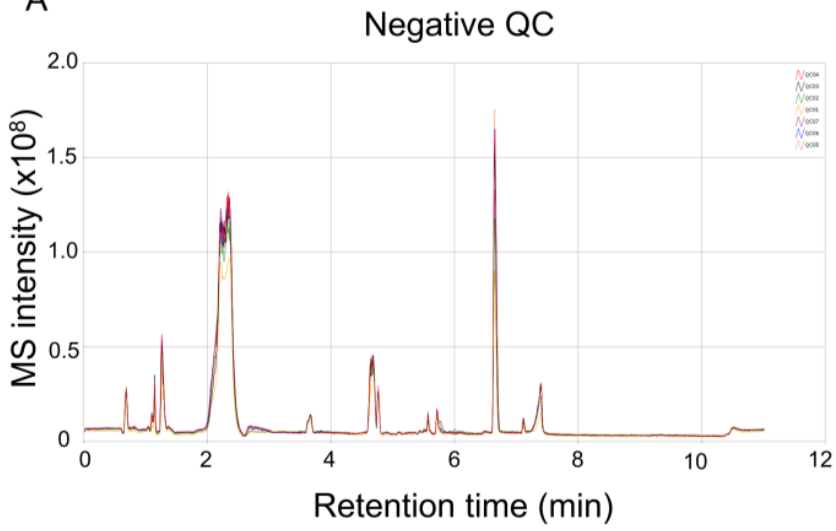

C
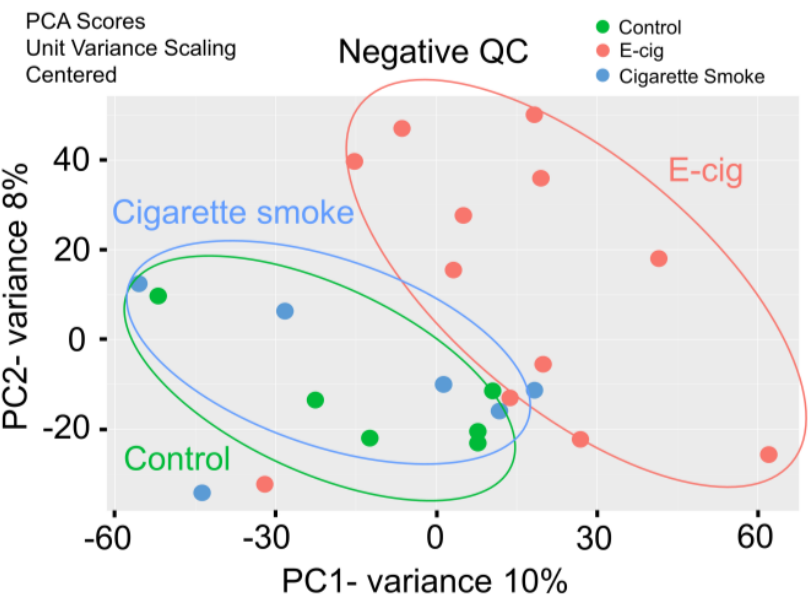

B

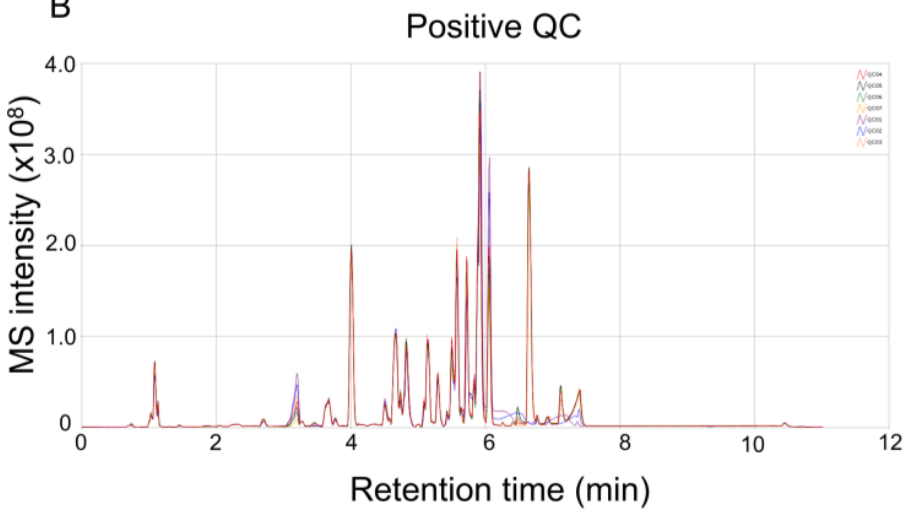

D

PCA Scores Control Unit Variance Scaling Positive QC $\quad$ E-cig

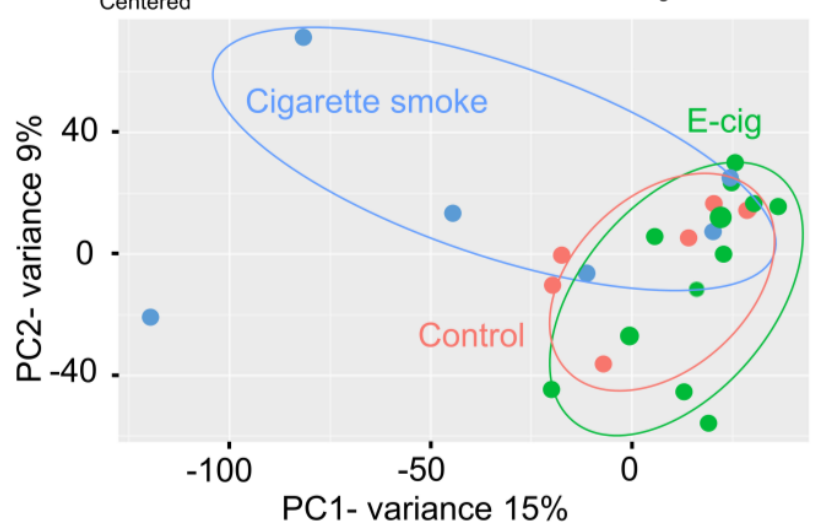

Figure 1. Metabolites from plasma were analyzed from ultra-performance liquid chromatography mass spectrometry (UPLC-MS). Spectra from UPLC-MS measured from (A) negative and (B) positive ion modes were used to identify individual metabolites. Score plots including all samples from principal component analysis (PCA) based on (C) negative and (D) positive ion modes presented dysregulated metabolomics affected by e-cig vaping and cigarette smoking.

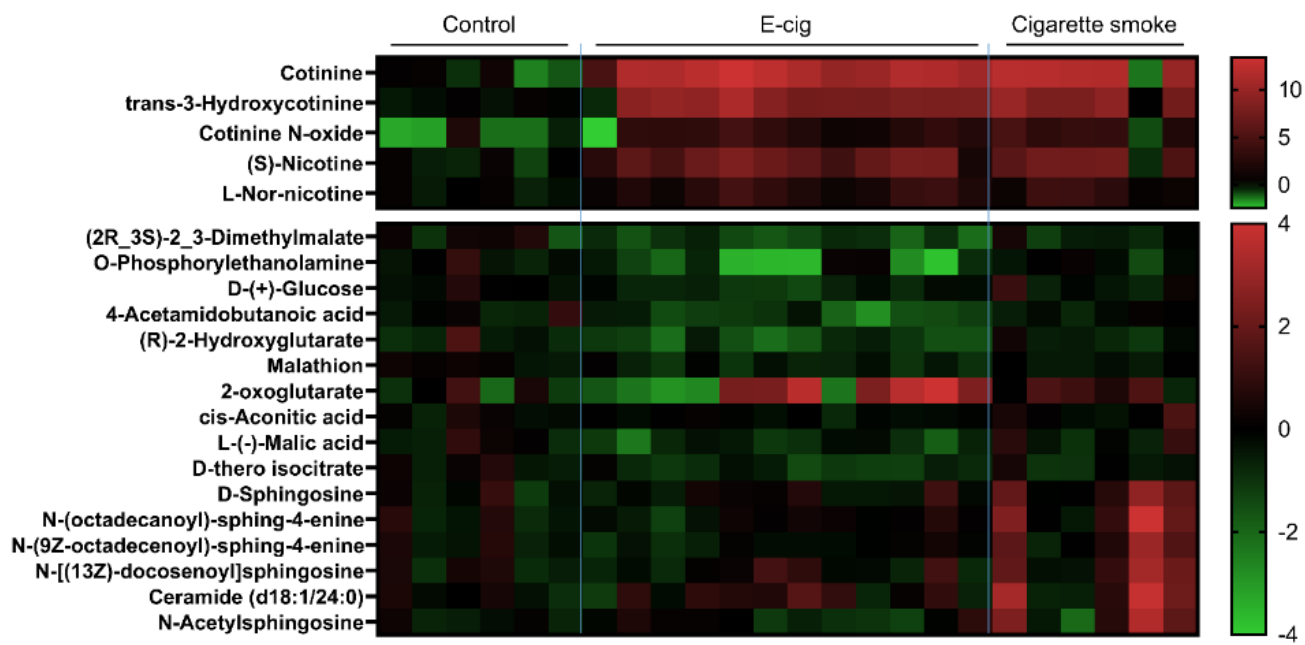

Figure 2. Metabolites from plasma were analyzed from UPLC-MS, metabolite fold changes were analyzed based on the normalized spectrum area. Heatmap representing significant dysregulated metabolites from nicotine degradation, TCA cycle, and sphingolipid metabolism among control $(n=6)$, e-cig $(n=12)$, and cigarette smoke $(n=6)$. Data are summarized as normalized $\log 2$ transformed. 
Table 1. Metabolic pathway dysregulation among non-smokers, e-cig users, and cigarette smokers.

\begin{tabular}{cccccccc}
\hline \multicolumn{3}{c}{ Control vs. E-Cigarette } & \multicolumn{3}{c}{ Control vs. Cigarette Smoke } \\
\hline Pathways & Overlap Size & Pathway Size & $\boldsymbol{p}$-Value & Pathways & Overlap Size & Pathway Size & $p$-Value \\
\hline Nicotine degradation III & 7 & 17 & 0.00361 & Nicotine degradation III & 6 & 17 \\
Serotonin degradation & 5 & 7 & 0.00106 & Serotonin degradation & 3 & 0.00042 \\
$\quad \begin{array}{c}\text { Gluconeogenesis } \\
\text { TCA cycle }\end{array}$ & 5 & 9 & 0.00138 & Gluconeogenesis & 4 & 7 & 0.00106 \\
$\begin{array}{c}\text { D-galactose degradation V } \\
\text { UDP-N-acetyl-D- }\end{array}$ & 6 & 9 & 0.00086 & nicotine degradation IV & 4 & 0.00094 \\
$\begin{array}{c}\text { galactosamine } \\
\text { biosynthesis II }\end{array}$ & 6 & 6 & 0.00087 & & & \\
\hline
\end{tabular}

2.2. Nicotine Degradation-Related Metabolites Increased in Both Plasma from Cigarette Smokers and E-Cig Users

Nicotine degradation is commonly seen after cigarette smoking and e-cig (with nicotine) vaping [28]. As expected, we have shown increased metabolites related to nicotine degradation in plasma from both e-cig users and cigarette smokers (Figure 3). Significantly increased metabolites were cotinine, cotinine N-oxide, L-nornicotine, (S)-nicotine, trans-3-hydroxycotinine, and (R)-6-hydroxynicotine (Figure 3). However, there was no significant difference between e-cig and cigarette smoke groups (Figure 3). L-Nornicotine, (R)-6-hydroxynicotine, and cotinine are the metabolic products converted from (S)-nicotine or nicotine; trans-3-hydroxycotinine and cotinine $\mathrm{N}$-oxide are the downstream metabolites converted from cotinine.
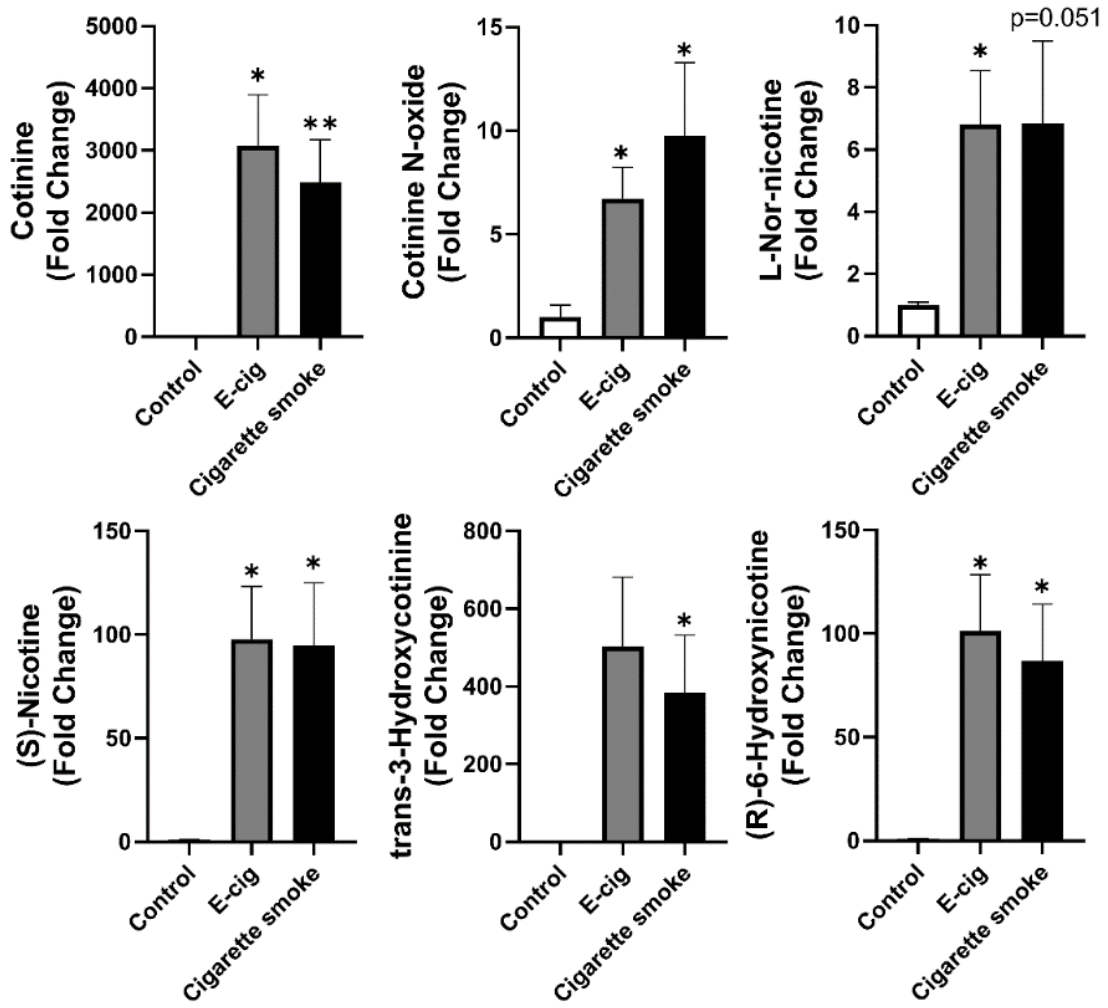

Figure 3. Metabolites from plasma analyzed from UPLC-MS from positive ion mode identified dysregulated nicotine degradation related metabolites in e-cig users and cigarette smokers. Fold changes were calculated based on the normalized area from UPLC-MS spectra, and control groups were used as a baseline. Data are shown as mean \pm SEM $(n=6$ for non-smoking control and cigarette smoke groups, $n=12$ for e-cig group; ${ }^{*} p<0.05,{ }^{* *} p<0.01$ vs. control non-smokers). 


\subsection{Metabolites Associated with TCA Cycles Dysregulated in Plasma from E-Cig Users}

Metabolites screened from the negative ion mode UPLC-MS were further identified, and we have shown that significant amounts of metabolites related to TCA cycles are statistically dysregulated in e-cig users' plasma compared to cigarette smokers' plasma (Figure 4). TCA cycle-related metabolites, such as (2R,3S)-2, 3-dimethylmalate, D-glucose, (R)-2hydroxyglutarate ((R)-2-HG), O-phosphorylethanolamine, malathion, D-threo-isocitrate, malic acid, and 4-acetamidobutanoic acid ( $\mathrm{N}$-acetyl-GABA), are significantly decreased in e-cig users' plasma compared to healthy controls or cigarette smokers (Figure 4). There was no change among groups for the concentration of cis-aconitic acid (Figure 4), and an increased plasma concentration of 2-oxoglutarate was found in e-cig users compared to control and cigarette smokers (Figure 4).
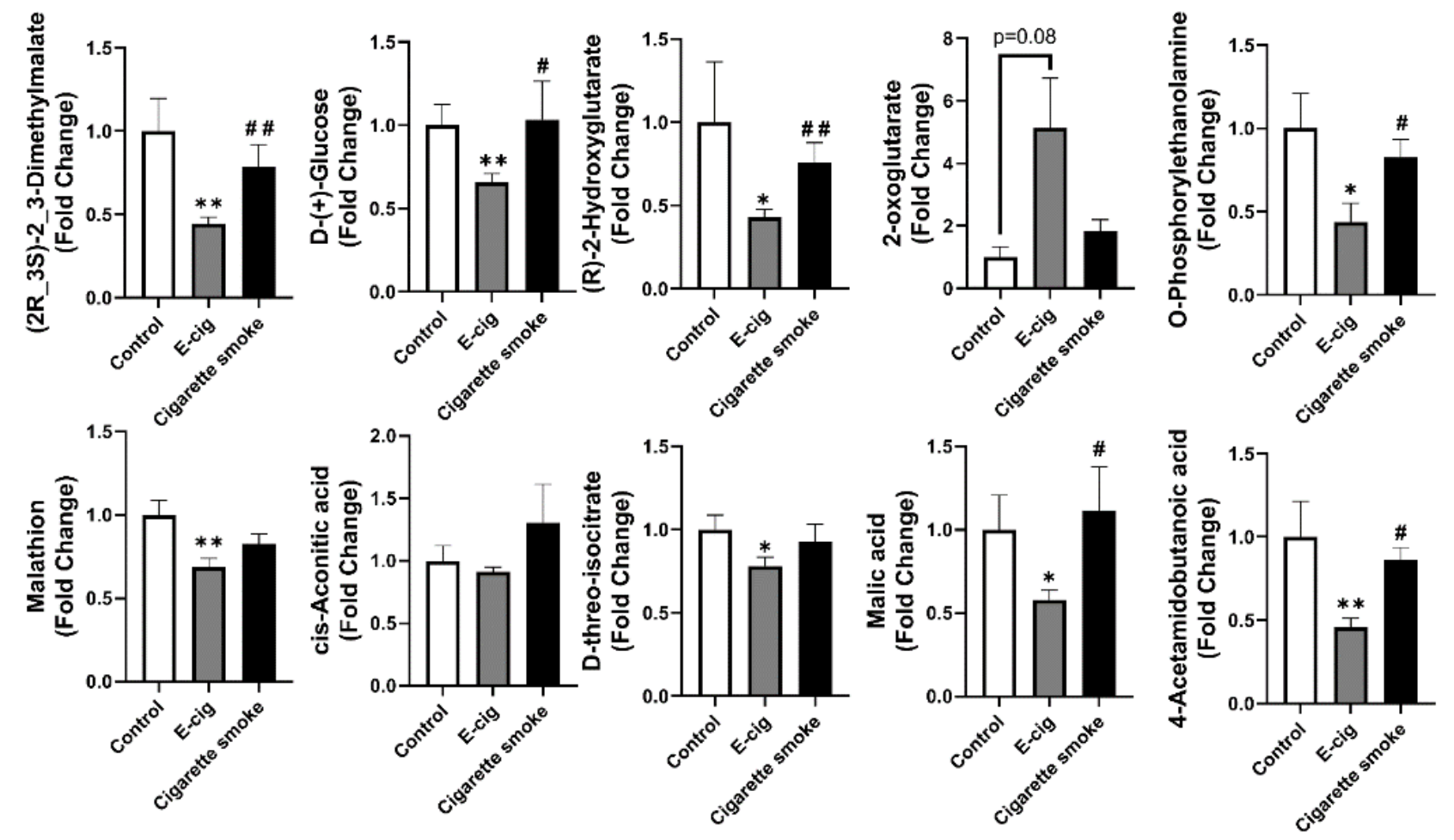

Figure 4. Metabolites from plasma analyzed from UPLC-MS from negative ion mode identified dysregulated TCA cycle related metabolites in e-cig users. Fold changes were calculated based on the normalized area from UPLC-MS spectra, and control groups were used as a baseline. Data are shown as mean $\pm \operatorname{SEM}(n=6$ for non-smoking control and cigarette smoke groups, $n=12$ for e-cig group; ${ }^{*} p<0.05,{ }^{* *} p<0.01$ vs. non-smoking control; $\# p<0.05$, \#\# $p<0.01$ vs. e-cig).

\subsection{Dysregulated Sphingolipid Metabolites Found in Plasma from Cigarette Smokers}

From the positive ion UPLC-MS analysis of screened metabolites, we have further shown that sphingolipid metabolites are dysregulated in cigarette smokers' plasma compared to e-cig users or healthy controls (Figure 5). The concentrations of D-sphingosine, $N$-(octadecanoyl)-sphing-4-enine, $N$-(9Z-octadecenoyl)-sphing-4-enine, ceramide, and $N$ [(13Z)-docosenoyl]sphingosine were found to be significantly increased in plasma from cigarette smokers compared to e-cig users and healthy controls (Figure 5). The concentration of $\mathrm{N}$-acetylsphingosine showed an increasing trend but not a significant difference between the cigarette smoke and control groups (Figure 5). 


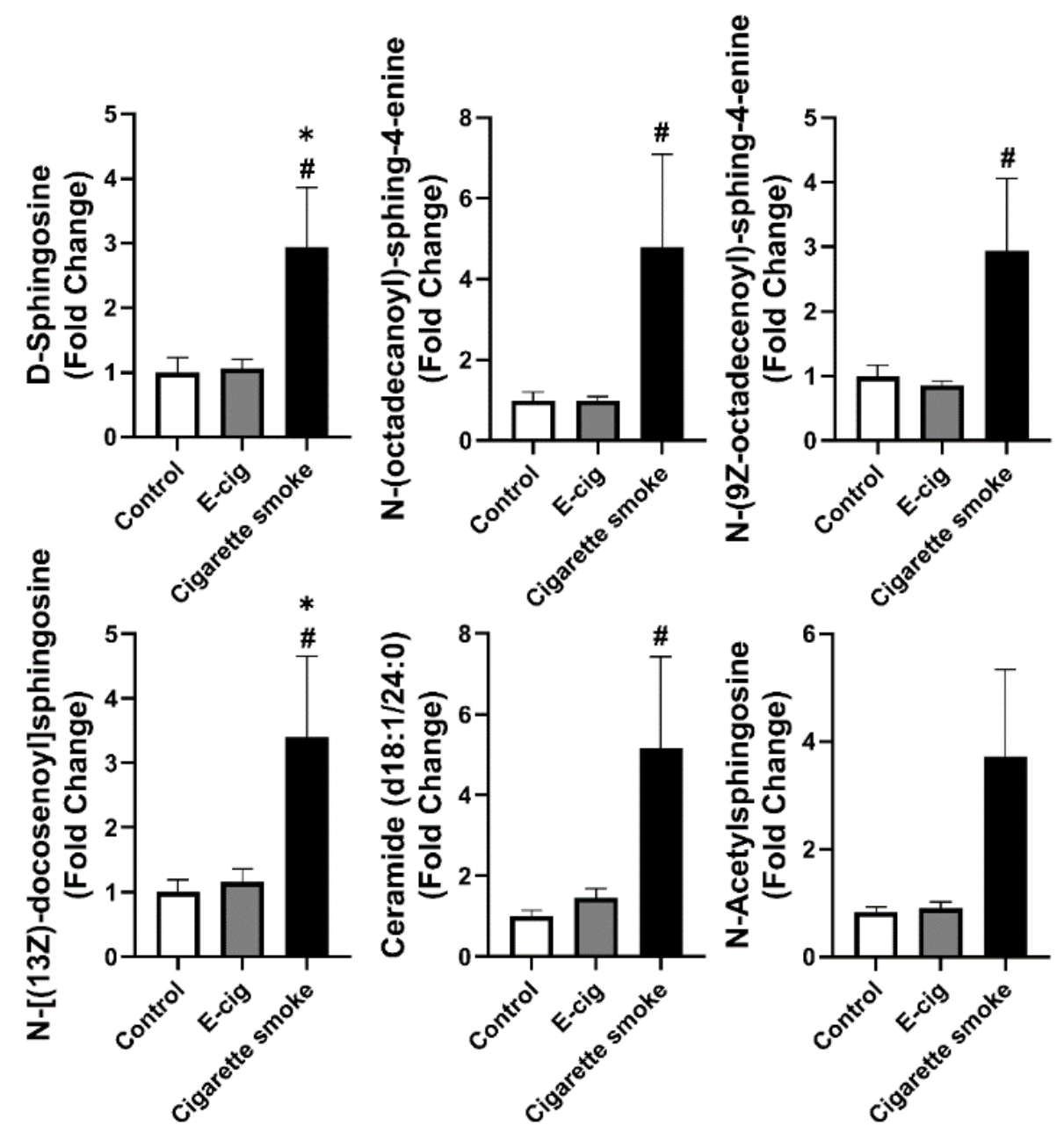

Figure 5. Metabolites from plasma analyzed from UPLC-MS from positive ion mode identified dysregulated sphingolipid metabolites in cigarette smokers. Fold changes were calculated based on the normalized area from UPLC-MS spectra, and control groups were used as a baseline. Data are shown as mean \pm SEM ( $n=6$ for non-smoking control and cigarette smoke groups, $n=12$ for e-cig group; * $p<0.05$ vs. non-smoking control; $\# p<0.05$ vs. e-cig).

\subsection{Other Dysregulated Metabolites in Plasma Identified from E-Cig Users or Cigarette Smokers}

In addition to the TCA cycle or sphingolipid metabolites, we also identified other significantly dysregulated metabolites (Figure 6). Among the metabolites significantly dysregulated in e-cig user's plasma, we observed DL-4-hydroxyphenyllactic acid and S(3-oxo-3-carboxy-n-propyl)cysteine were decreased in e-cig users compared to cigarette smokers and healthy controls (Figure 6). We found significantly increased metabolites such as glycolic acid, 6-hydroxy-2-naphthoic acid, 2-beta-D-glucosyle anthranilate, and budesonide, as well as significantly downregulated metabolites such as L-(-)-methionine, 2-methylthiazolidine, 4-(stearoylamino)butanoic acid, and 3-methylsulfolene (Figure 6). 

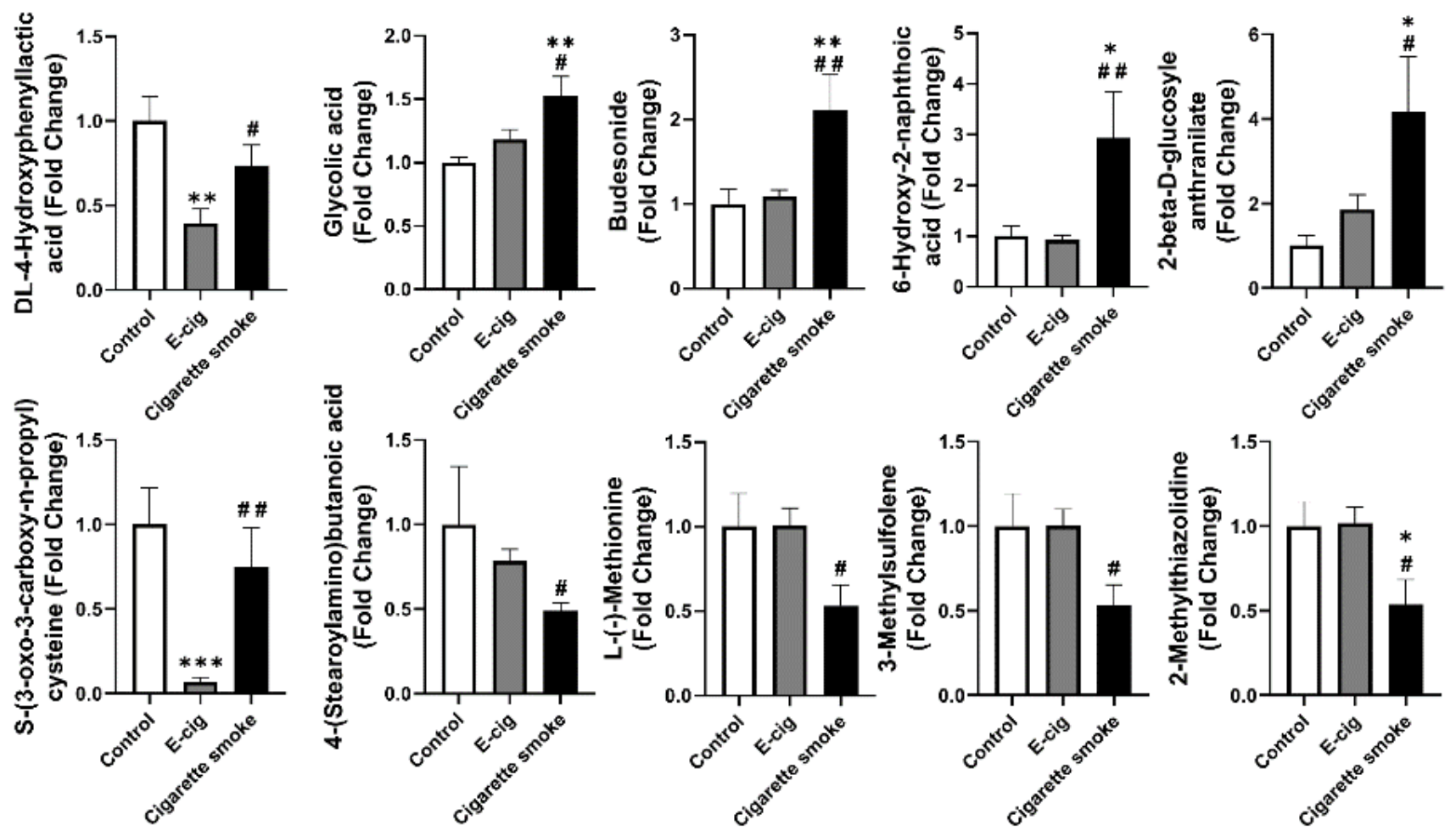

Figure 6. Metabolites from plasma analyzed from UPLC-MS from both negative and positive ion mode identified dysregulated metabolites in either e-cig users or cigarette smoker. Fold changes were calculated based on the normalized area from UPLC-MS spectra, and control groups were used as a baseline. Data are shown as mean $\pm \operatorname{SEM}(n=6$ for non-smoking control and cigarette smoke groups, $n=12$ for e-cig group; ${ }^{*} p<0.05,{ }^{* *} p<0.01$ vs. non-smoking control; \# $p<0.05$, \#\# $p<0.01$ vs. e-cig).

\section{Discussion}

E-cig vaping has rapidly increased since it has been presumed as a safe alternative to cigarette smoke, evoking public concerns about the health risks of e-cig vaping [29]. Our previous studies have shown that acute and chronic e-cig exposure can induce pulmonary inflammation and oxidative stress [30,31]. Many studies have shown that cigarette smoking induces metabolic disease with dysregulated metabolites [9,32]; however, limited studies have elucidated the effects of e-cig on metabolic disorders, which identify promising metabolite biomarkers related to potential diseases $[32,33]$. In this study, we have identified dysregulated metabolites from the plasma of e-cig users and cigarette smokers related to nicotine degradation, the TCA cycle, and sphingolipid metabolism as well as some other metabolites caused by e-cig vape aerosol and cigarette smoke.

Nicotine degradation pathways are the most commonly activated metabolic responses in cigarette smokers and e-cig users (nicotine-contained in e-cig vaping). When nicotine from cigarettes and e-cig aerosols was inhaled into the human body, a number of metabolites are metabolized from nicotine [28]. The most important and commonly used metabolite to identify nicotine degradation is cotinine, which is converted from $70-80 \%$ of nicotine introduced into the human body [28]. The other cotinine-associated metabolites identified from our study, including cotinine $\mathrm{N}$-oxide and trans-3-hydroxycotinine. Around $35 \sim 42 \%$ of the total cotinine will be transformed to cotinine N-oxide and trans-3hydroxycotinine [28]. Nicotine-related metabolites, such as nornicotine and 6-hydroxynicotine, will be converted from nicotine [28]. About $10 \%$ of the nicotine will not be metabolized, and we have detected it as (S)-nicotine, and [28]. Cotinine has been used as a biomarker to identify nicotine degradation, which is the commonly activated metabolism after smoking and nicotine vaping [30,34]. Furthermore, nicotine, cotinine, cotinine N-oxide, and trans3-hydroxycotinine are considered primary metabolites in total nicotine equivalent (TNE), 
which have been used as standards to validate nicotine intake [35]. Other metabolites such as nornicotine and 6-hydroxynicotine are less concentrated $(<2 \%)$ and lower in abundance than TNE metabolites [28]. Hence, they are not considered as regular biomarkers for the characterization of nicotine inhalation [28,35,36]. A previous study has identified that nornicotine preserves a longer half-life than nicotine or cotinine [37], and nornicotine was highly relevant to TNE in smokers' urine than health control [37]. Consistent with these data, our results confirm that although nornicotine or 6-hydroxynicotine are low abundances in body fluids, they are still sufficient to serve as biomarkers to identify the smoking status and an indicator for nicotine degradation pathway activation.

The TCA cycle is a series of biochemical conversions with the generation of bioenergy, which usually occurs in mitochondrion with the products from glycolysis. A previous study has shown that PG or PG/VG inhibited glucose metabolism and ATP generation in airway epithelium [38]. The aerosolized PG/VG inhaled into lungs were unlikely deposited and accumulated in the bloodstream since the half-life for PG is $\sim 4 \mathrm{~h}$; PG will be converted to lactic acid via alcohol dehydrogenase in the liver and then merged in the TCA cycle [19]. Our previous studies described that e-cig exposure can induce oxidative stress in the mitochondrion and dysregulation of mitochondrial complexes in lung fibroblasts [39]. Furthermore, e-cig exposure causes an increased amount of damaged mitochondrial DNA in plasma as well as increases the risk of cardiovascular diseases [18]. In this study, we showed that most of the TCA cycle-related metabolites are downregulated in e-cig users while there were no changes in the cigarette smokers compared to the healthy controls. A decreased (R)-2-HG level in e-cig users was found, and (R)-2HG has been proved to exhibit as an oncometabolite which is capable of inhibiting tumor growth [40]. E-cig vaping downregulated the level of (R)-2HG in plasma indirectly reveals the risk of carcinogenesis associated with vaping, and (R)-2HG can serve as a biomarker for identifying e-cig vaping and cancers [40]. We also found a lower plasma level of (2R,3S)-2,3-dimethylmalate in e-cig users compared to cigarette smokers and healthy controls, and (2R,3S)-2,3-dimethylmalate can serve as a precursor of pyruvate, which is a basic substrate for the TCA cycle. A decreased level of (2R,3S)-2,3-dimethylmalate is in line with the TCA cycle substrates we have discussed above, and it is a promising biomarker for reflecting e-cig vaping inducing inhibition of bioenergy synthesis and mitochondrial respiration.

This is the first study to report that various metabolites associated with the TCA cycle are altered in e-cig users, since former studies are focused on nicotine-related metabolites identified from e-cig users. Surprisingly, we did not find a significant difference between the cigarette smokers and the healthy controls about the TCA cycle metabolites in plasma. It is well known that cigarette smoke inhibits mitochondrial respiratory function and dysregulates the TCA cycle [15]. The dysregulated TCA cycle-related metabolites identified from the e-cig group provide information that vaping might associate with synthetic bioenergy metabolism. Therefore, a larger sample size is needed for future studies.

Sphingolipid metabolites are associated with lung inflammation, emphysema, and COPD [22,27]. Among all the known sphingolipid metabolites, sphingosine-1-phosphate (S1P) and ceramide are well-studied [20]. Increased ceramide levels found in the elastaseinduced mouse emphysema model and ceramides inhibitors were capable of attenuating elastase caused airspace enlargement [41,42]. We found that the cigarette smoke group showed significantly higher plasma levels of ceramide and sphingosine than ecig users and the healthy controls. Since chronic cigarette smoking is shown to cause COPD/emphysema, our results are indirectly in agreement with previous studies [41-43]. Additionally, ceramide accumulation and the disproportion of sphingolipids were identified from the lungs of COPD/emphysema patients and smokers [44]. We have observed increased sphingosine as well, which can be converted from S1P, which is one of the downstream products of ceramide. Both ceramide and S1P are involved in the pathogenesis of various lung diseases [22,45], which allows sphingosine to have great potentiality as a biomarker for lung disorders associated with cigarette smoke. Other sphingolipid metabolites, such as $N$-(octadecanoyl)-sphing-4-enine, $N$-(9Z-octadecenoyl)-sphing-4-enine, and 
$\mathrm{N}$-[(13Z)-docosenoyl]sphingosine are also promising biomarkers for lung injury induced by cigarette smoke.

Both cigarette smoking and e-cig vaping have been associated with increasing risks of cardiovascular diseases [46,47]. Nicotinic metabolites are the major metabolites after smoking and vaping. Nicotine has been identified to promote myocardial remodeling and fibrosis, increase the risk of sudden heart failure and tachycardia/ventricular fibrillation, and upregulate blood pressure [48]. Our results show increased nicotinic metabolites in ecig users and cigarette smokers, emphasizing that both e-cig vaping and cigarette smoking increases the risks of cardiovascular diseases. Other than nicotinic metabolites, we have identified dysregulated TCA cycle-related metabolites, such as citric acid, L-malic acid, and N-acetyl-GABA, in e-cig users compared to control. Citric acid and L-malic acid have been proved with a protective effect on ischemic heart diseases [49]. N-acetyl-GABA is a metabolite of GABA that can regulate cardiovascular stress induced by hypertension, and a decreased GABA reflects the vulnerability of hypertensive heart disease [50]. Significant upregulation of sphingolipid metabolites in cigarette smokers was identified in this study, and a recent clinical report described serum sphingolipids as biomarkers of cardiovascular disease [51]. In our cohort, we found increased serum ceramide (d18:1/24:0) levels in cigarette smokers, and ceramide (d18:1/24:0) has been reported as a predictor for the risk of myocardial infarcts and stroke [52]. Our results emphasize that elevated sphingolipids in cigarette smokers could serve as biomarkers for cardiovascular diseases.

We have also identified other metabolites dysregulated in either e-cig users or cigarette smokers. We found a decreased L-(-)-methionine in cigarette smokers' plasma compared to e-cig users and healthy controls. A lower level of L-(-)-methionine was identified with increased metabolic rates, weight loss, and increased risk of acute myocardial infarction, which have also been shown in cigarette smokers [53-55]. Our results describe the possibility that dysregulated metabolites from cigarette smokers or e-cig users are associated with predicting the pathogenesis of cardiovascular diseases.

Despite identifying specific metabolites associated with e-cig vaping and cigarette smoking, the other contributing factors other than e-cig or cigarette smoke possibly affect the results. From our study, we noticed neither sex- nor age-dependent manner alterations of metabolites. However, e-cig device brands, e-liquid ingredients, smoking/vaping duration, and smoking/vaping habits affect the specificity and accuracy of the outcomes. The e-liquid basic ingredients, such as humectants present in commercially available products, are similar to each other, and no significant difference was noticed in puffing topography throughout different studies [56,57]. Hence, we do not expect significant contributors to dysregulated metabolites except specifically for vaping and smoking per se. However, a larger sample volume is required to minimize the random errors introduced by other confounders, and more detailed subject screening criteria should be standardized to understand the role of other contributing factors to metabolomics. We have matched the mass spectrum against with our local database to ensure the features of identified metabolites, and cross-comparison with the online database could also be of benefit by improving our results and minimizing the false-positive identifications [58].

In conclusion, various dysregulated metabolites were identified from e-cig users and cigarette smokers compared to healthy controls/non-smokers. Dysregulated metabolites from both e-cig users and cigarette smokers were correlated with nicotine degradation. Dysregulated metabolites related to the TCA cycle were found only in e-cig users, and altered sphingolipid metabolites were shown only in cigarette smokers; specific dysregulated metabolites identified in different groups serve as novel biomarkers for vaping and smoking associated with metabolic diseases. Further biochemical measurements of altered metabolites are required to confirm our findings in a larger cohort. 


\section{Methods and Materials}

\subsection{Human Subjects}

Participants in this study have provided information including age, sex, gender, and ethnicity. Detailed information about cigarette smoking, e-cig vaping, and health control allowed us to categorize the condition groups as described previously [59]. In brief, we established the following criteria to screen potential participants in different categories: (1) ages in between 21 and 65 years old; (2) healthy control subjects are defined as never having used tobacco products (cigarette smoke, waterpipe smoke, and cigar) or any e-cig products; (3) e-cig users as defined as never having used any tobacco products; (4) there is no history of chronic diseases in any of our participants; (5) there are no current respiratory infections or any anti-inflammatory/corticosteroid drugs in use in any of our subjects; (6) female participants are not currently breastfeeding or pregnant. Written informed consents were required from all participants, and individual subject information (age, sex, and ethnicity) was obtained through a questionnaire and verbal communication (Table 2).

Table 2. Patient information for subjects.

\begin{tabular}{cccc}
\hline Group & Non-Smokers & E-Cigarette Users & Cigarette Smokers \\
\hline Age & $43.17 \pm 7.00$ & $40.50 \pm 4.24$ & $44.00 \pm 4.59$ \\
Sex (Male/Female) & $3 / 3$ & $6 / 6$ & $3 / 3$ \\
Ethnicity & & & \\
Caucasian/White & $66.67 \%$ & $41.67 \%$ & $83.33 \%$ \\
African American & $16.67 \%$ & $25.00 \%$ & $16.67 \%$ \\
Asian & $16.67 \%$ & $8.33 \%$ & 0 \\
N/A & $0.00 \%$ & $25.00 \%$ & 0 \\
\hline
\end{tabular}

\subsection{Plasma Samples Collection}

Blood samples were spin down at room temperature for $5 \mathrm{~min}, 1000 \mathrm{rpm}$, then transfer the plasma into a new tube and stored at $-80^{\circ} \mathrm{C}$ [60] for UPLC-MS analysis.

\subsection{Chemicals}

Methanol (LC-MS-grade, Fisher Scientific Inc, Pittsburgh, PA, USA), isopropanol (LC-MS-grade, Fisher Scientific Inc, Pittsburgh, PA, USA), acetonitrile (LC-MS-grade, Fisher Scientific Inc, Pittsburgh, PA, USA), water (LC-MS-grade, Fisher Scientific Inc, Pittsburgh, PA, USA), formic acid (99.5+\%) (LC-MS-grade, Fisher Scientific Inc, Pittsburgh, PA, USA), ammonium acetate (LC-MS-grade, Fisher Scientific Inc, Pittsburgh, PA, USA), and ammonium hydroxide (LC-MS-grade, Fisher Scientific Inc, Pittsburgh, PA, USA) were used for preparation of mobile phases and solutions.

\subsection{UPLC-MS Analysis}

UPLC-MS analyses were performed at the Mass Spectrometry Core Facility at Georgia Institute of Technology according to previously described protocols [60].

In brief, samples were separated through chromatography with Ultimate 3000 UPLC (Thermo Fisher Scientific, Inc., Waltham, MA, USA) system with a Waters ACQUITY UPLC $\mathrm{BEH}$ C18, $2.1 \times 50 \mathrm{~mm}, 1.7 \mu \mathrm{m}$ particle column as reverse phase (RP) separation with water/acetonitrile (40:60 $v / v)$ as mobile phase A, and acetonitrile/2-propanol (10:90 v/v) as mobile phase $\mathrm{B}$, and total $10 \mathrm{mM}$ ammonium formate and $0.1 \%$ formic acid additives were used to elevate the metabolites identification efficiency by a Q-Exactive HF Orbitrap mass spectrometer (Thermo Fisher Scientific, Inc., Waltham, MA, USA) [60]. The mobile phases included. For, In parallel, samples were separated via hydrophilic interaction chromatography (HILIC) with Waters ACQUITY UPLC HILIC, C18, $2.1 \times 50 \mathrm{~mm}, 1.7 \mu \mathrm{m}$ particle column, and water/acetonitrile (95:5 $\mathrm{v} / \mathrm{v}), 10 \mathrm{mM}$ ammonium acetate, and $0.05 \%$ ammonium hydroxide as mobile phase $\mathrm{A}$, and acetonitrile with $0.05 \%$ ammonium hydroxide were used for mobile phase B [60]. Metabolites identifications were based on the spectrum from mass spectrometer (Thermo Fisher Scientific, Inc., Waltham, MA, USA). 
During sample processing, column temperature maintained at $55^{\circ} \mathrm{C}$, while samples were kept at $5{ }^{\circ} \mathrm{C}$ with auto-injection with the volumes of 5 and $2 \mu \mathrm{L}$ in RP and HILIC methods, respectively as described previously [60].

After sample separation and mass-spectrometer identification, we applied top five data-dependent acquisition (DDA) to collected MS/MS spectrum at stepped normalized collision energy (NCE) of 10, 30, and $50 \mathrm{~V}$. A parallel reaction monitoring (PRM) processing, were carried out at NCE from 10 to $40 \mathrm{~V}$ to reveal complete metabolites profiling [60].

\subsection{Data Processing}

Compound Discoverer v2.1 (Thermo Fisher Scientific, Inc., Waltham, MA, USA) and XCMS software were both used to identified the exact metabolites [60]. In brief, we applied the software to analyze our raw data set, and chromatographic alignment was performed, then peak picking and peak area integration were processed for metabolites quantification, followed by QC-based compound area normalization to quantify metabolite dysregulations [60]. Retention times $<0.5 \mathrm{~min}$ (Reverse phase) and $<0.9 \mathrm{~min}$ (HILIC) were not considered as unreliable identification. The screening criteria for differential metabolic indicators include $p<0.05$, fold change $>2$, or $<0.5$ as described [60]. Welch's t-test with a Benjamini-Hochberg correction was applied to cigarette smoke vs. control, and E-cig user vs. control, and corrected with a $p$-value $<0.05$ was considered a significant difference. A further selection of dysregulated metabolic pathways in the above cohorts was based on overlap size (>6). The tentative ID configuration based on spectral (MS2) matching against the database was performed [60] to minimize false-positive identifications (Table 3).

Table 3. Spectral (MS2) matching description of dysregulated metabolites.

\begin{tabular}{|c|c|c|c|c|c|c|c|c|}
\hline Name & $\begin{array}{l}\text { Confidence } \\
\text { Level * }\end{array}$ & $\begin{array}{l}\text { Neutral } \\
\text { Elemental } \\
\text { Formula }\end{array}$ & $\begin{array}{c}\text { Average } \\
\text { Neutral } \\
\text { MW }\end{array}$ & $\begin{array}{l}\text { Average } \\
\text { RT }\end{array}$ & $\begin{array}{l}\text { Ion Type } \\
\text { Detected }\end{array}$ & $\begin{array}{c}\text { Theoretical } \\
\text { Neutral } \\
\text { Mass }\end{array}$ & $\begin{array}{l}\text { Mass } \\
\text { Error } \\
\text { (ppm) }\end{array}$ & Description \\
\hline Cotinine & 2 & $\mathrm{C}_{10} \mathrm{H}_{12} \mathrm{~N}_{2} \mathrm{O}$ & 176.0950 & 2.70 & {$[\mathrm{M}+\mathrm{H}]^{+}$} & 176.0950 & 0.0 & $\begin{array}{l}\text { MS2 matched to } \\
\text { MZCloud }\end{array}$ \\
\hline Cotinine N-oxide & 2 & $\mathrm{C}_{10} \mathrm{H}_{12} \mathrm{~N}_{2} \mathrm{O}_{2}$ & 192.0899 & 4.45 & {$[\mathrm{M}+\mathrm{H}]^{+}$} & 192.0899 & 0.0 & $\begin{array}{l}\text { MS2 matched to } \\
\text { MZCloud }\end{array}$ \\
\hline L-Nornicotine & 3 & $\mathrm{C}_{9} \mathrm{H}_{12} \mathrm{~N}_{2}$ & 148.1001 & 4.53 & {$[\mathrm{M}+\mathrm{H}]^{+}$} & 148.1000 & 0.7 & $\begin{array}{c}\text { Two RT } 4.530 \text { and } \\
5.374\end{array}$ \\
\hline (S)-Nicotine & 2 & $\mathrm{C}_{10} \mathrm{H}_{14} \mathrm{~N}_{2}$ & 162.1157 & 5.47 & {$[\mathrm{M}+\mathrm{H}]^{+}$} & 162.1157 & 0.0 & $\begin{array}{l}\text { MS2 matched to } \\
\text { MZCloud }\end{array}$ \\
\hline trans-3-Hydroxycotinine & 2 & $\mathrm{C}_{10} \mathrm{H}_{12} \mathrm{~N}_{2} \mathrm{O}_{2}$ & 192.0899 & 2.65 & {$[\mathrm{M}+\mathrm{H}]^{+}$} & 192.0899 & 0.0 & $\begin{array}{l}\text { MS2 matched to } \\
\text { MZCloud }\end{array}$ \\
\hline (R)-6-Hydroxynicotine & 3 & $\mathrm{C}_{10} \mathrm{H}_{14} \mathrm{~N}_{2} \mathrm{O}$ & 178.1106 & 6.00 & {$[\mathrm{M}+\mathrm{H}]^{+}$} & 178.1106 & 0.0 & $\begin{array}{l}\text { MS2 matched to } \\
\text { MZCloud }\end{array}$ \\
\hline $\begin{array}{c}(2 \mathrm{R}, 3 \mathrm{~S})-2,3- \\
\text { Dimethylmalate }\end{array}$ & 3 & $\mathrm{C}_{6} \mathrm{H}_{10} \mathrm{O}_{5}$ & 162.0526 & 1.35 & {$[\mathrm{M}-\mathrm{H}]^{-}$} & 162.0528 & -1.2 & No MS/MS \\
\hline D-(+)-Glucose & 2 & $\mathrm{C}_{6} \mathrm{H}_{12} \mathrm{O}_{6} \cdot \mathrm{H}_{2} \mathrm{CO}_{2}$ & 226.0688 & 3.27 & {$\left[\mathrm{M}+\mathrm{HCO}_{2}\right]^{-}$} & 226.0689 & -0.4 & $\begin{array}{c}\text { MS2 matched at } \\
226.0689 \mathrm{M}+\mathrm{H}_{2} \mathrm{CO}_{2} \\
\text { MS2 matched to }\end{array}$ \\
\hline (R)-2-Hydroxyglutarate & 3 & $\mathrm{C}_{5} \mathrm{H}_{8} \mathrm{O}_{5}$ & 148.0371 & 1.41 & {$[\mathrm{M}-\mathrm{H}]^{-}$} & 148.0372 & -0.7 & $\begin{array}{c}\text { MZCloud (two RT } \\
1.409 \text { and } 2.769 \text { ) }\end{array}$ \\
\hline 2-Oxoglutarate & 2 & $\mathrm{C}_{5} \mathrm{H}_{6} \mathrm{O}_{5}$ & 146.0214 & 1.98 & {$[\mathrm{M}-\mathrm{H}]^{-}$} & 146.0215 & -0.7 & $\begin{array}{l}\text { MS2 matched to } \\
\text { MZCloud }\end{array}$ \\
\hline $\begin{array}{c}\text { O- } \\
\text { Phosphorylethanolamine }\end{array}$ & 2 & $\mathrm{C}_{2} \mathrm{H}_{8} \mathrm{NO}_{4} \mathrm{P}$ & 141.0190 & 6.47 & {$[\mathrm{M}-\mathrm{H}]^{-}$} & 141.0191 & -0.7 & $\begin{array}{l}\text { MS2 matched to } \\
\text { MZCloud }\end{array}$ \\
\hline Malathion & 3 & $\mathrm{C}_{10} \mathrm{H}_{19} \mathrm{O}_{6} \mathrm{PS}_{2}$ & 330.0361 & 7.44 & {$[\mathrm{M}-\mathrm{H}]^{-}$} & 330.0361 & 0.0 & $\begin{array}{l}\text { man-made } \\
\text { insecticide }\end{array}$ \\
\hline cis-Aconitic acid & 2 & $\mathrm{C}_{6} \mathrm{H}_{6} \mathrm{O}_{6}$ & 174.0162 & 0.84 & {$[\mathrm{M}-\mathrm{H}]^{-}$} & 174.0164 & -1.1 & $\begin{array}{c}\text { MS2 matched to } \\
\text { MZCloud (3 RT } \\
0.843,1.195,2.169)\end{array}$ \\
\hline D-threo-Isocitrate & 4 & $\mathrm{C}_{6} \mathrm{H}_{8} \mathrm{O}_{7}$ & 192.02687 & 6.72 & {$[\mathrm{M}-\mathrm{H}]^{-}$} & 192.0270 & - & 8 peaks $5.387-7.169$ \\
\hline Malic acid & 2 & $\mathrm{C}_{4} \mathrm{H}_{6} \mathrm{O}_{5}$ & 134.0216 & 1.36 & {$[\mathrm{M}-\mathrm{H}]^{-}$} & 134.0215 & 0.7 & $\begin{array}{l}\text { MS2 matched to } \\
\text { MZCloud }\end{array}$ \\
\hline 4-Acetamidobutanoic acid & 2 & $\mathrm{C}_{6} \mathrm{H}_{11} \mathrm{NO}_{3}$ & 145.0739 & 1.56 & {$[\mathrm{M}+\mathrm{H}]^{+}$} & 145.0739 & 0.0 & $\begin{array}{l}\text { MS2 matched to } \\
\text { MZCloud }\end{array}$ \\
\hline
\end{tabular}


Table 3. Cont.

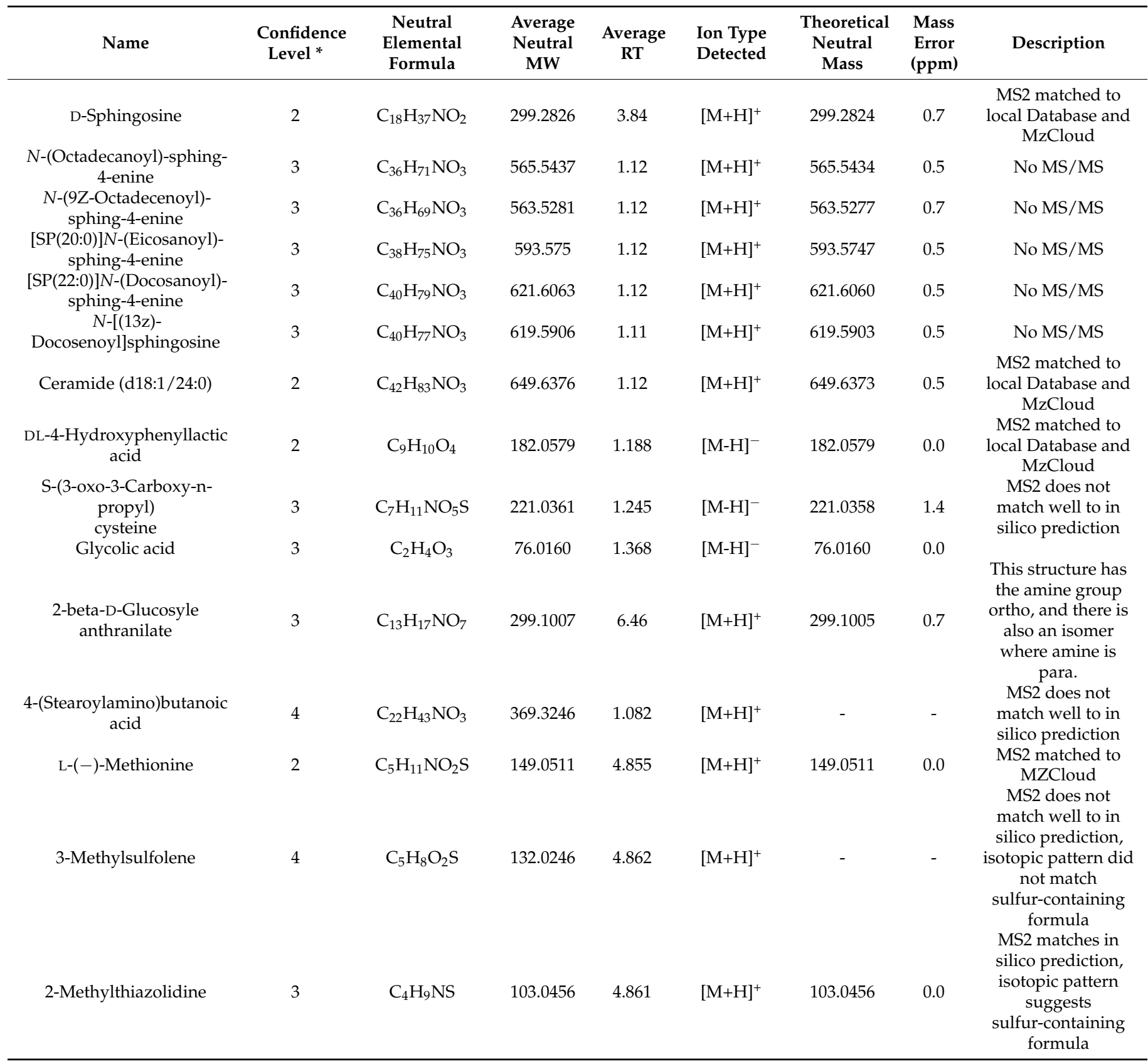

* Confidence Levels: (1) Match to authentic standard; (2) Match to MS/MS spectra in public database (MzCloud, ThermoFisher Scientific, Waltham, MA, USA); (3) Match to accurate mass in public database (Chemspider) or internal mass list; and (4) Unknown.

The fold change of specific metabolite was calculated based on the normalized area from positive or negative mode spectra. In brief, normalized areas from the control group were averaged and used as the baseline. The individual normalized area from different samples was divided by the averaged normalized area from the control group as fold change compared to the baseline.

\subsection{Statistical Analysis}

One-way ANOVA and Student's $t$-test were used here to determine the significant difference in the change fold of metabolites among groups through GraphPad Prism Software version 8.0 (La Jolla, San Diego, CA, USA). Data were presented as mean $\pm \mathrm{SEM}$, and $p<0.05$ was considered as a statistical difference. 
Author Contributions: Q.W. and I.R. conceived and designed the experiments; Q.W. and X.J. conducted experiments; Q.W. and X.J. analyzed the data; Q.W., X.J. and I.R. wrote and revised/edited the manuscript. All authors have read and agreed to the published version of the manuscript.

Funding: This study was supported by the NIH 1R01HL135613 (I.R), and FAMRI foundation YFEL141014 (X.J.).

Institutional Review Board Statement: This study was conducted at general clinical research center of the University of Rochester Medical Center (URMC) with IRB approval (RSRB00064337/ RSRB\#00063526) along with the URMC Institutional Biosafety Committee approval (study approval number: Rahman/102054/09-167/07-186). Participants in this study have provided information including age, sex, gender, and ethnicity. Detailed information about cigarette smoking, e-cig vaping, and health control allowed us to categorize the condition groups as described previously.

Informed Consent Statement: Informed consent was obtained from all subjects involved in the study as described previously [59].

Data Availability Statement: The availability of all data presented in this study is from authors upon request.

Acknowledgments: This work was supported by Georgia Institute of Technology's Systems Mass Spectrometry Core Facility.

Conflicts of Interest: The authors declare no conflict of interest.

\section{References}

1. Patel, D.; Davis, K.C.; Cox, S.; Bradfield, B.; King, B.A.; Shafer, P.; Caraballo, R.; Bunnell, R. Reasons for current E-cigarette use among U.S. adults. Prev. Med. 2016, 93, 14-20. [CrossRef]

2. Madison, M.C.; Landers, C.T.; Gu, B.-H.; Chang, C.-Y.; Tung, H.-Y.; You, R.; Hong, M.J.; Baghaei, N.; Song, L.-Z.; Porter, P.; et al. Electronic cigarettes disrupt lung lipid homeostasis and innate immunity independent of nicotine. J. Clin. Investig. 2019, 129, 4290-4304. [CrossRef] [PubMed]

3. Goniewicz, M.L.; Kuma, T.; Gawron, M.; Knysak, J.; Kosmider, L. Nicotine Levels in Electronic Cigarettes. Nicotine Tob. Res. 2012, 15, 158-166. [CrossRef] [PubMed]

4. Grana, R.A.; Popova, L.; Ling, P.M. A Longitudinal Analysis of Electronic Cigarette Use and Smoking CessationElectronic Cigarette Use and Smoking CessationLetters. JAMA Intern. Med. 2014, 174, 812-813. [CrossRef] [PubMed]

5. Muthumalage, T.; Friedman, M.R.; McGraw, M.D.; Ginsberg, G.; Friedman, A.E.; Rahman, I. Chemical Constituents Involved in E-Cigarette, or Vaping Product Use-Associated Lung Injury (EVALI). Toxics 2020, 8, 25. [CrossRef]

6. Centers for Disease Control and Prevention. Publications and Reports of the Surgeon General. In How Tobacco Smoke Causes Disease: The Biology and Behavioral Basis for Smoking-Attributable Disease: A Report of the Surgeon General; Centers for Disease Control and Prevention (US): Atlanta, GA, USA, 2010.

7. Górna, I.; Napierala, M.; Florek, E. Electronic Cigarette Use and Metabolic Syndrome Development: A Critical Review. Toxics 2020, 8, 105. [CrossRef] [PubMed]

8. Hsu, P.C.; Zhou, B.; Zhao, Y.; Ressom, H.W.; Cheema, A.K.; Pickworth, W.; Shields, P.G. Feasibility of identifying the tobaccorelated global metabolome in blood by UPLC-QTOF-MS. J. Proteome Res. 2013, 12, 679-691. [CrossRef]

9. Gu, F.; Derkach, A.; Freedman, N.D.; Landi, M.T.; Albanes, D.; Weinstein, S.J.; Mondul, A.M.; Matthews, C.E.; Guertin, K.A.; Xiao, Q.; et al. Cigarette smoking behaviour and blood metabolomics. Int. J. Epidemiol. 2016, 45, 1421-1432. [CrossRef]

10. Sun, K.; Liu, J.; Ning, G. Active smoking and risk of metabolic syndrome: A meta-analysis of prospective studies. PLoS ONE 2012, 7, e47791. [CrossRef]

11. Hukkanen, J.; Jacob, P., III; Benowitz, N.L. Metabolism and disposition kinetics of nicotine. Pharmacol. Rev. 2005, 57, 79-115. [CrossRef]

12. Cross, A.J.; Boca, S.; Freedman, N.D.; Caporaso, N.E.; Huang, W.Y.; Sinha, R.; Sampson, J.N.; Moore, S.C. Metabolites of tobacco smoking and colorectal cancer risk. Carcinogenesis 2014, 35, 1516-1522. [CrossRef] [PubMed]

13. Khan, N.A.; Lawyer, G.; McDonough, S.; Wang, Q.; Kassem, N.O.; Kas-Petrus, F.; Ye, D.; Singh, K.P.; Kassem, N.O.F.; Rahman, I. Systemic biomarkers of inflammation, oxidative stress and tissue injury and repair among waterpipe, cigarette and dual tobacco smokers. Tob. Control. 2020, 29 (Suppl. S2), s102. [CrossRef] [PubMed]

14. Singh, K.P.; Maremanda, K.P.; Li, D.; Rahman, I. Exosomal microRNAs are novel circulating biomarkers in cigarette, waterpipe smokers, E-cigarette users and dual smokers. BMC Med. Genom. 2020, 13, 128. [CrossRef] [PubMed]

15. Solanki, H.S.; Babu, N.; Jain, A.P.; Bhat, M.Y.; Puttamallesh, V.N.; Advani, J.; Raja, R.; Mangalaparthi, K.K.; Kumar, M.M.; Prasad, T.S.K.; et al. Cigarette smoke induces mitochondrial metabolic reprogramming in lung cells. Mitochondrion 2018, 40, 58-70. [CrossRef]

16. Agarwal, A.R.; Yin, F.; Cadenas, E. Short-term cigarette smoke exposure leads to metabolic alterations in lung alveolar cells. Am. J. Respir. Cell Mol. Biol. 2014, 51, 284-293. [CrossRef] 
17. Lerner, C.A.; Sundar, I.K.; Yao, H.; Gerloff, J.; Ossip, D.J.; McIntosh, S.; Robinson, R.; Rahman, I. Vapors produced by electronic cigarettes and e-juices with flavorings induce toxicity, oxidative stress, and inflammatory response in lung epithelial cells and in mouse lung. PLOS ONE 2015, 10, e0116732. [CrossRef]

18. Li, J.; Huynh, L.; Cornwell, W.D.; Tang, M.-S.; Simborio, H.; Huang, J.; Kosmider, B.; Rogers, T.J.; Zhao, H.; Steinberg, M.B.; et al. Electronic Cigarettes Induce Mitochondrial DNA Damage and Trigger TLR9 (Toll-Like Receptor 9)-Mediated Atherosclerosis. Arter. Thromb. Vasc. Biol. 2021, 41, 839-853. [CrossRef]

19. Fowles, J.R.; Banton, M.I.; Pottenger, L.H. A toxicological review of the propylene glycols. Crit. Rev. Toxicol. 2013, 43, 363-390. [CrossRef]

20. Maceyka, M.; Spiegel, S. Sphingolipid metabolites in inflammatory disease. Nature 2014, 510, 58-67. [CrossRef]

21. Chun, J.; Hartung, H.P. Mechanism of action of oral fingolimod (FTY720) in multiple sclerosis. Clin. Neuropharmacol. 2010, 33, 91-101. [CrossRef]

22. Ghidoni, R.; Caretti, A.; Signorelli, P. Role of Sphingolipids in the Pathobiology of Lung Inflammation. Mediators Inflamm. 2015, 2015, 487508. [CrossRef]

23. Petrache, I.; Medler, T.R.; Richter, A.T.; Kamocki, K.; Chukwueke, U.; Zhen, L.; Gu, Y.; Adamowicz, J.; Schweitzer, K.S.; Hubbard, W.C.; et al. Superoxide dismutase protects against apoptosis and alveolar enlargement induced by ceramide. Am. J. Physiol. Lung Cell Mol. Physiol. 2008, 295, L44-L53. [CrossRef] [PubMed]

24. Mizumura, K.; Justice, M.J.; Schweitzer, K.S.; Krishnan, S.; Bronova, I.; Berdyshev, E.V.; Hubbard, W.C.; Pewzner-Jung, Y.; Futerman, A.H.; Choi, A.M.K.; et al. Sphingolipid regulation of lung epithelial cell mitophagy and necroptosis during cigarette smoke exposure. FASEB J. 2018, 32, 1880-1890. [CrossRef] [PubMed]

25. Petrusca, D.N.; Gu, Y.; Adamowicz, J.J.; Rush, N.I.; Hubbard, W.C.; Smith, P.A.; Berdyshev, E.V.; Birukov, K.G.; Lee, C.H.; Tuder, R.M.; et al. Sphingolipid-mediated inhibition of apoptotic cell clearance by alveolar macrophages. J. Biol. Chem. 2010, 285, 40322-40332. [CrossRef] [PubMed]

26. Alberg, A.J.; Armeson, K.; Pierce, J.S.; Bielawski, J.; Bielawska, A.; Visvanathan, K.; Hill, E.G.; Ogretmen, B. Plasma sphingolipids and lung cancer: A population-based, nested case-control study. Cancer Epidemiol. Biomark. Prev. 2013, 22, 1374-1382. [CrossRef] [PubMed]

27. Bowler, R.P.; Jacobson, S.; Cruickshank, C.; Hughes, G.J.; Siska, C.; Ory, D.S.; Petrache, I.; Schaffer, J.E.; Reisdorph, N.; Kechris, K. Plasma sphingolipids associated with chronic obstructive pulmonary disease phenotypes. Am. J. Respir. Crit. Care Med. 2015, 191, 275-284. [CrossRef] [PubMed]

28. Benowitz, N.L.; Hukkanen, J.; Jacob, P., III. Nicotine chemistry, metabolism, kinetics and biomarkers. In Handbook of Experimental Pharmacology; Springer: Berlin/Heidelberg, Germany, 2009; pp. $29-60$.

29. Tegin, G.; Mekala, H.M.; Sarai, S.K.; Lippmann, S. E-Cigarette Toxicity? South Med. J. 2018, 111, 35-38. [CrossRef]

30. Wang, Q.; Sundar, I.K.; Li, D.; Lucas, J.H.; Muthumalage, T.; McDonough, S.R.; Rahman, I. E-cigarette-induced pulmonary inflammation and dysregulated repair are mediated by nAChR $\alpha 7$ receptor: Role of nAChR $\alpha 7$ in SARS-CoV-2 Covid-19 ACE2 receptor regulation. Respir. Res. 2020, 21, 154. [CrossRef]

31. Wang, Q.; Ahmad Khan, N.; Muthumalage, T.; Lawyer, G.R.; McDonough, S.R.; Chuang, T.-D.; Gong, M.; Sundar, I.K.; Rehan, V.K.; Rahman, I. Dysregulated repair and inflammatory responses by e-cigarette-derived inhaled nicotine and humectant propylene glycol in a sex-dependent manner in mouse lung. FASEB Bioadv. 2019, 1, 609-623. [CrossRef]

32. Schick, S.F.; Blount, B.C.; Jacob, P.; Saliba, N.A.; Bernert, J.T.; El Hellani, A.; Jatlow, P.; Pappas, R.S.; Wang, L.; Foulds, J.; et al. Biomarkers of exposure to new and emerging tobacco delivery products. Am. J. Physiol. Lung Cell. Mol. Physiol. 2017, 313, L425-L452. [CrossRef]

33. Jacob, P.; St Helen, G.; Yu, L.; Nardone, N.; Havel, C.; Cheung, P.; Benowitz, N.L. Biomarkers of Exposure for Dual Use of Electronic Cigarettes and Combustible Cigarettes: Nicotelline, NNAL, and Total Nicotine Equivalents. Nicotine Tob. Res. Off. J. Soc. Res. Nicotine Tob. 2020, 22, 1107-1113. [CrossRef]

34. Xu, X.; Su, Y.; Fan, Z.H. Cotinine concentration in serum correlates with tobacco smoke-induced emphysema in mice. Sci. Rep. 2014, 4, 3864. [CrossRef]

35. Wang, L.; Bernert, J.T.; Benowitz, N.L.; Feng, J.; Jacob, P., III; McGahee, E.; Caudill, S.P.; Scherer, G.; Scherer, M.; Pluym, N.; et al. Collaborative Method Performance Study of the Measurement of Nicotine, Its Metabolites, and Total Nicotine Equivalents in Human Urine. Cancer Epidemiol. Biomark. Prev. 2018, 27, 1083-1090. [CrossRef] [PubMed]

36. Benowitz, N.L. Nicotine addiction. N. Engl. J. Med. 2010, 362, 2295-2303. [CrossRef] [PubMed]

37. von Weymarn, L.B.; Thomson, N.M.; Donny, E.C.; Hatsukami, D.K.; Murphy, S.E. Quantitation of the Minor Tobacco Alkaloids Nornicotine, Anatabine, and Anabasine in Smokers' Urine by High Throughput Liquid Chromatography-Mass Spectrometry. Chem. Res. Toxicol. 2016, 29, 390-397. [CrossRef] [PubMed]

38. Woodall, M.; Jacob, J.; Kalsi, K.K.; Schroeder, V.; Davis, E.; Kenyon, B.; Khan, I.; Garnett, J.P.; Tarran, R.; Baines, D.L. E-cigarette constituents propylene glycol and vegetable glycerin decrease glucose uptake and its metabolism in airway epithelial cells in vitro. Am. J. Physiol. Lung Cell. Mol. Physiol. 2020, 319, L957-L967. [CrossRef]

39. Lerner, C.A.; Rutagarama, P.; Ahmad, T.; Sundar, I.K.; Elder, A.; Rahman, I. Electronic cigarette aerosols and copper nanoparticles induce mitochondrial stress and promote DNA fragmentation in lung fibroblasts. Biochem. Biophys. Res. Commun. 2016, 477, 620-625. [CrossRef] 
40. Su, R.; Dong, L.; Li, C.; Nachtergaele, S.; Wunderlich, M.; Qing, Y.; Deng, X.; Wang, Y.; Weng, X.; Hu, C.; et al. R-2HG Exhibits Anti-tumor Activity by Targeting FTO/m6A/MYC/CEBPA Signaling. Cell 2018, 172, 90-105.e23. [CrossRef]

41. Petrache, I.; Natarajan, V.; Zhen, L.; Medler, T.R.; Richter, A.T.; Cho, C.; Hubbard, W.C.; Berdyshev, E.V.; Tuder, R.M. Ceramide upregulation causes pulmonary cell apoptosis and emphysema-like disease in mice. Nat. Med. 2005, 11, 491-498. [CrossRef]

42. Tibboel, J.; Reiss, I.; de Jongste, J.C.; Post, M. Ceramides: A potential therapeutic target in pulmonary emphysema. Respir. Res. 2013, 14, 96. [CrossRef]

43. Liu, D.; Meister, M.; Zhang, S.; Vong, C.I.; Wang, S.; Fang, R.; Li, L.; Wang, P.G.; Massion, P.; Ji, X. Identification of lipid biomarker from serum in patients with chronic obstructive pulmonary disease. Respir. Res. 2020, 21, 242. [CrossRef] [PubMed]

44. Bodas, M.; Pehote, G.; Silverberg, D.; Gulbins, E.; Vij, N. Autophagy augmentation alleviates cigarette smoke-induced CFTRdysfunction, ceramide-accumulation and COPD-emphysema pathogenesis. Free Radic. Biol. Med. 2019, 131, 81-97. [CrossRef] [PubMed]

45. Mohammed, S.; Harikumar, K.B. Sphingosine 1-Phosphate: A Novel Target for Lung Disorders. Front. Immunol. 2017, 8, 296. [CrossRef] [PubMed]

46. Buchanan, N.D.; Grimmer, J.A.; Tanwar, V.; Schwieterman, N.; Mohler, P.J.; Wold, L.E. Cardiovascular risk of electronic cigarettes: A review of preclinical and clinical studies. Cardiovasc. Res. 2019, 116, 40-50. [CrossRef] [PubMed]

47. Pittilo, M. Cigarette smoking, endothelial injury and cardiovascular disease. Int. J. Exp. Pathol. 2000, 81, 219-230. [CrossRef]

48. Benowitz, N.L.; Burbank, A.D. Cardiovascular toxicity of nicotine: Implications for electronic cigarette use. Trends Cardiovasc. Med. 2016, 26, 515-523. [CrossRef]

49. Tang, X.; Liu, J.; Dong, W.; Li, P.; Li, L.; Lin, C.; Zheng, Y.; Hou, J.; Li, D. The cardioprotective effects of citric Acid and L-malic Acid on myocardial ischemia/reperfusion injury. Evid. Based Complement. Alternat. Med. 2013, 2013, 820695. [CrossRef] [PubMed]

50. Ma, P.; Li, T.; Ji, F.; Wang, H.; Pang, J. Effect of GABA on blood pressure and blood dynamics of anesthetic rats. Int. J. Clin. Exp. Med. 2015, 8, 14296-14302.

51. Poss, A.M.; Maschek, J.A.; Cox, J.E.; Hauner, B.J.; Hopkins, P.N.; Hunt, S.C.; Holland, W.L.; Summers, S.A.; Playdon, M.C. Machine learning reveals serum sphingolipids as cholesterol-independent biomarkers of coronary artery disease. J. Clin. Investig. 2020, 130, 1363-1376. [CrossRef]

52. Hilvo, M.; Vasile, V.C.; Donato, L.J.; Hurme, R.; Laaksonen, R. Ceramides and Ceramide Scores: Clinical Applications for Cardiometabolic Risk Stratification. Front. Endocrinol. 2020, 11, 570628. [CrossRef]

53. Yu, D.; Yang, S.E.; Miller, B.R.; Wisinski, J.A.; Sherman, D.S.; Brinkman, J.A.; Tomasiewicz, J.L.; Cummings, N.E.; Kimple, M.E.; Cryns, V.L.; et al. Short-term methionine deprivation improves metabolic health via sexually dimorphic, mTORC1-independent mechanisms. FASEB J. 2018, 32, 3471-3482. [CrossRef]

54. Metsios, G.S.; Stavropoulos-Kalinoglou, A.; Nevill, A.M.; Douglas, K.M.; Koutedakis, Y.; Kitas, G.D. Cigarette smoking significantly increases basal metabolic rate in patients with rheumatoid arthritis. Ann. Rheum. Dis. 2008, 67, 70-73. [CrossRef]

55. Dhar, I.; Lysne, V.; Seifert, R.; Svingen, G.F.T.; Ueland, P.M.; Nygård, O.K. Plasma methionine and risk of acute myocardial infarction: Effect modification by established risk factors. Atherosclerosis 2018, 272, 175-181. [CrossRef]

56. National Academies of Sciences, Engineering, and Medicine. Public Health Consequences of E-Cigarettes; Eaton, D.L., Kwan, L.Y., Stratton, K., Eds.; National Academies Press (US): Washington, DC, USA, 2018.

57. Zhu, S.-H.; Sun, J.Y.; Bonnevie, E.; Cummins, S.E.; Gamst, A.; Yin, L.; Lee, M. Four hundred and sixty brands of e-cigarettes and counting: Implications for product regulation. Tob. Control. 2014, 23 (Suppl. S3), iii3. [CrossRef] [PubMed]

58. Sumner, L.W.; Amberg, A.; Barrett, D.; Beale, M.H.; Beger, R.; Daykin, C.A.; Fan, T.W.; Fiehn, O.; Goodacre, R.; Griffin, J.L.; et al. Proposed minimum reporting standards for chemical analysis Chemical Analysis Working Group (CAWG) Metabolomics Standards Initiative (MSI). Metab. Off. J. Metab. Soc. 2007, 3, 211-221.

59. Singh, K.P.; Lawyer, G.; Muthumalage, T.; Maremanda, K.P.; Khan, N.A.; McDonough, S.R.; Ye, D.; McIntosh, S.; Rahman, I. Systemic biomarkers in electronic cigarette users: Implications for noninvasive assessment of vaping-associated pulmonary injuries. ERJ Open Res. 2019, 5, 00182-2019. [CrossRef] [PubMed]

60. Huang, D.; Gaul, D.A.; Nan, H.; Kim, J.; Fernández, F.M. Deep Metabolomics of a High-Grade Serous Ovarian Cancer TripleKnockout Mouse Model. J. Proteome Res. 2019, 18, 3184-3194. [CrossRef] [PubMed] 